\title{
Evaluation of Dietary Habits and Lifestyle on the Prevalence of Metabolic Syndrome and Obesity in Undergraduate University Students in Cameroon: A Cross Sectional Study
}

Solange Dabou ${ }^{1}$, Phélix Bruno Telefo ${ }^{1^{\star}}$ and Leonard Fonkeng Sama ${ }^{2}$

${ }^{1}$ Laboratory of Biochemistry, Medicinal Plants, Food Security and Nutritional Sciences (LABPMAN), University of Dschang, Dschang, Cameroon, P.O. Box 67, Dschang, Cameroon

${ }^{2}$ Laboratory of Microbiology and Antimicrobial Substances (LAMAS), University of Dschang, Dschang, Cameroon, P.O. Box 67, Dschang, Cameroon

"Corresponding author: Phélix BrunoTelefo, Laboratory of Biochemistry, Medicinal Plants, Food Security and Nutritional Sciences (LABPMAN), University of Dschang, Dschang, Cameroon, P.O. Box 67, Dschang, Cameroon, Tel: 00237677827183; E-mail: bphelix@yahoo.co.uk

Received date: January 03, 2018; Accepted date: January 22, 2018; Published date: January 26, 2018

Copyright: @ 2018 Dabou S, et al. This is an open-access article distributed under the terms of the creative commons attribution license, which permits unrestricted use, distribution, and reproduction in any medium, provided the original author and source are credited.

\section{Abstract}

Background: Obesity and metabolic syndrome have nowadays a widespread dissemination around the world. Their prevalence is increasing in developing countries, due to modifications in dietary habits and lifestyle. Limited data exist on those issues among school going youths in Cameroon.

Methods: A cross-sectional study including 203 consenting Cameroonian freshmen was conducted at the medical center of the University of Dschang. Anthropometric measurements, blood pressure, fasting blood glucose and lipid profile markers were measured using standard procedures. Metabolic syndrome was diagnosed using a harmonized definition while obesity diagnosis used BMI criterion. Dietary and lifestyle habits were recorded using a questionnaire.

Results: The prevalence of obesity and metabolic syndrome were $3.94 \%$ and $11.33 \%$ respectively. We found strong associations between the prevalence of metabolic syndrome and high frequency of consumption of "Koki" (OR=9.9, 95\% Cl: 7.09-14.04, $\mathrm{P}=0.0000)$, "Achu soup" ( $\mathrm{OR}=7.3,95 \% \mathrm{Cl}: 4.4-12.3, \mathrm{P}=0.0000)$, corn couscous $(\mathrm{OR}=5.64,95 \% \mathrm{Cl}: 4.34-7.33, \mathrm{P}=0.0000)$, "Ndolè" ( $\mathrm{OR}=2.4,95 \% \mathrm{Cl}: 1.9-3.05, \mathrm{P}=0.0000)$. Regular consumption of green vegetables is associated with low prevalence of metabolic syndrome $(\mathrm{OR}=0.4,95 \% \mathrm{Cl}$ : 0.2-0.3, $\mathrm{P}=0.0000)$. There is also a strong association between prevalence of obesity and high number of meal per day $(\mathrm{OR}=5.1,95 \%$ $\mathrm{Cl}: 3.07-8.4, \mathrm{P}=0.0000)$ as well as more than 6 hours of TV watching per day $(\mathrm{OR}=4.9,95 \% \mathrm{Cl}: 2.8-7.09$, $\mathrm{P}=0.0000)$.

Conclusion: Metabolic syndrome is present in young Cameroonians and is associated to certain dietary and lifestyle habits. Interventions targeting youth may therefore be multiplied with special concern on those dietary and lifestyle issues.

Keywords: Metabolic syndrome; Obesity; Dietary habits; Students

\section{Some Definitions}

Achu soup: Also known as, yellow soup is made up with palm oil, limestone and a variation of spices. (Homemade food)

Koki: Bean cake, made up with Vigna unguiculata subsp. Unguiculata ("black-eyed pea") paste and palm oil. (Homemade food)

Ndolè: Sauce, made up with large amounts of groundnuts (Arachis hypogea L.), and leaves of plants from the genus Vernona. (Homemade food)

List of Abbreviations BMI: Body Mass Index; DBP: Diastolic Blood Pressure; HDL-C: High Density Lipoprotein- Cholesterol; MSRS: Metabolic Syndrome Risk Score; OR: Odd Ratio; SBP: Systolic Blood Pressure; TG: Triglycerides; WC: Waist Circumference

\section{Introduction}

Overweight and obesity are becoming the most common human health problem of this century, paving the way for obesity related diseases, especially metabolic syndrome. The metabolic syndrome is defined as a cluster of cardiometabolic risk factors, which occur together more often than by chance alone [1]. That clustering of risk factors, including central obesity, insulin resistance, hypertension and dyslipidemia is unequivocally linked to an increased risk of developing type 2 diabetes and cardiovascular disease [1]. Metabolic syndrome contributes to an increase in the health care cost, which is a significant burden to countries throughout the world [2]. Metabolic syndrome as well as obesity have become serious issues in developed countries and their initiation is attributed to a degree of genetic predisposition created by multiple genes coupled with a sedentary lifestyle and a diet containing excess calories. Those societies promote and maintain chronic overconsumption of calories and physically inactive lifestyles $[3,4]$. However, the obesity "epidemic" is not limited to developed countries. In less developed countries such as Cameroon, obesity, metabolic syndrome and other obesity related disorders are more of a 
Citation: Dabou S, Telefo PB, Leonard Sama F (2018) Evaluation of Dietary Habits and Lifestyle on the Prevalence of Metabolic Syndrome and Obesity in Undergraduate University Students in Cameroon: A Cross Sectional Study. J Metabolic Synd 7: 236. doi: $10.4172 / 2167-0943.1000236$

Page 2 of 6

concern. These countries experience a rise of non-communicable diseases in urban settings. Moreover, soaring urbanization is accompanied by rapid lifestyle changes, leading to nutrition transition with progressive westernization of diets and sedentary lifestyle $[5,6]$. In the case of Cameroon, the prevalence of obesity and metabolic syndrome is reaching worrying proportions, affecting both adults and youths and leading to an impaired quality of life and a lowering of life expectancy [7]. The patterns of nutrition transition are observed there. It consists on an abandon of green vegetable sauces and fruits consumption for high calories food [8,9]. Besides, new evidence suggest that metabolic syndrome starts from childhood and rising incidence of obesity on young children and teenagers, leads to the emergence of cardiometabolic risk factors, previously described only on adults [10,11]. In Africa, several studies have shown relatively high prevalence of obesity on youth: $10 \%$ in Nigeria, $25.3 \%$ to $59.4 \%$ in Egypt, $10.8 \%-24 \%$ in South Africa and 3.6\% in Cameroon [7,12]; a situation that may limit the efficiency of cardiovascular diseases and type 2 diabetes prevention policies. Indeed, Africa has the world's largest proportion of youth and $70 \%$ of premature deaths in the world occur because of behaviors that started on teenage [13]. Consequently, special concerns on the issues of obesity and metabolic syndrome on young African generations must be considered. But, epidemiological data and scientific evidence concerning obesity and metabolic syndrome on youth are still insufficient in Africa and more in Cameroon. Therefore, the present study determined the prevalence of obesity and metabolic syndrome in Cameroonian youth and its relationship with their dietary habits and lifestyle.

\section{Methods}

\section{Study sample and design}

The study was cross-sectional and was carried out among first year university students. We examined, at a unique meeting session, 307 volunteers of both sex aged 15-25 years. Participants that had not observed at least 8 hours overnight fast (because of fasting plasma glucose and lipids determinations), or who were reported to have cardiovascular diseases were excluded from the study. Following this, we considered a final sample of 203 students for the study.

\section{Questionnaire}

Under the supervision of well-trained and qualified technicians, participants were invited through a face-to-face interview to fill a food frequency questionnaire. The questionnaire also recorded their age, gender, lifestyle habits (alcohol, cigarette consumption, level of physical activity, watching television time), and personal medical history of cardiovascular diseases.

\section{Anthropometry parameters}

The weight was recorded using scale $\left(\mathrm{SECA}^{\oplus}\right)$ to the nearest $0.1 \mathrm{~kg}$. Height was measured with a height gauge to the nearest $0.1 \mathrm{~cm}$. Waist circumference (WC) measurements to the nearest $0.1 \mathrm{~cm}$ were taken on standing subjects midway between the lowest rib and iliac crest using a flexible non-expandable tape measure. The Body Mass Index (BMI) was calculated by the formula BMI $=$ Weight $(\mathrm{kg}) / \mathrm{Height}^{2}(\mathrm{~m})$ and expressed as $\mathrm{kg} / \mathrm{m}^{2}$. A BMI $\geq 25$ defined overweight and a BMI $\geq$ 30 defined obesity [8]. A waist circumference $\geq 94$ in men and $\geq 80$ in women defined central obesity [1].

\section{Arterial blood pressure measurements}

Blood pressure (BP) was measured with an Automatic Blood Pressure Monitor with Heart Sense (One Plus Healthcare ${ }^{\varpi}$ FT-11B) in a sitting position after at least 10 minutes rest and two measurements were taken after 5 minutes intervals. The average of the two measurements was used to assess blood pressure level.

\section{Blood sampling}

In the morning following 8-hour overnight fast, $5 \mathrm{ml}$ of venous blood was collected on dry tubes by venipuncture on the left hand from each participant. The serum was obtained by centrifugation and aliquots were frozen at $-20^{\circ} \mathrm{C}$ for subsequent biochemical analyses.

\section{Biochemical analyses}

Fasting blood glucose was directly measured from blood collected at the participant's fingertip through Glucose deshydrogenasequinoprotein method using a glucometer (Accucheck Active $^{\otimes}$ ) and glucose test trips (Accu-check ${ }^{\circledR}$ ). The concentration of plasma total cholesterol, HDL cholesterol and triglycerides were measured with standard enzymatic spectrophotometric method $[14,15]$ using MonLab ${ }^{\bullet}$ Diagnostic Kits.

\section{Diagnosis of metabolic syndrome}

The criteria for metabolic syndrome [1] were as follows:(1) WC $\geq 94$ $\mathrm{cm}$ for men and $\geq 80 \mathrm{~cm}$ for women (central obesity). (2) elevated TGs $\geq 150 \mathrm{mg} / \mathrm{dl}(1.7 \mathrm{mmol} / \mathrm{L})$. (3) reduced HDL-C $<40 \mathrm{mg} / \mathrm{dl}(1.0$ $\mathrm{mmol} / \mathrm{L})$ in men and $<50 \mathrm{mg} / \mathrm{dl}(1.3 \mathrm{mmol} / \mathrm{L})$ in women. (4) elevated blood pressure [systolic blood pressure (SBP) $\geq 130$ or diastolic (DBP) $\geq 85 \mathrm{mmHg}$ ] and/or treatment of previously diagnosed hypertension] and elevated plasma fasting glucose $\geq 100 \mathrm{mg} / \mathrm{dl}$. A metabolic syndrome risk score (MSRS) was calculated for each study participant. The MSRS ranged from a score of 0 to 5. Those participants who scored three to five risk factors were determined to have metabolic syndrome.

\section{Statistical analysis}

Statistical analyses were done using statistical package for social sciences (SPSS) Windows version 17.0. Descriptive analysis results are presented as mean values \pm standard deviations for continuous variables. Frequencies are expressed in terms of percentage, and compared using Fisher exact test. Student test (t-test) was used to compare the means of continuous variables. The association between the factors and the prevalence of metabolic syndrome or obesity was analyzed by the chi-squared test. Logistic regressions adjusted for age were performed to evaluate the association between independent variables and metabolic syndrome or obesity. The criterion for statistical significance was set at $\mathrm{p}<0.05$.

\section{Results}

The mean age and standard deviation of the 203 individuals was 20 \pm 2.35 years. The gender ratio was $57.14 \%$ men vs $42.56 \%$ women. As indicated in Table 1, the prevalence of overweight, obesity, central obesity and metabolic syndrome was $23.15 \%, 3.94 \%, 16.75 \%$ and $11.33 \%$ respectively. The prevalence of these four parameters appeared to be significantly higher in women than in men (Table 1). Indeed, men appeared to be less affected by metabolic syndrome $(\mathrm{OR}=0.2,95 \%$ CI: 0.06-0.1, $\mathrm{P}=0.0000)$, obesity ( $\mathrm{OR}=0.09,95 \% \mathrm{CI}$ : 0.08-0.1, $\mathrm{P}=0.0000$ ) 
Citation: Dabou S, Telefo PB, Leonard Sama F (2018) Evaluation of Dietary Habits and Lifestyle on the Prevalence of Metabolic Syndrome and Obesity in Undergraduate University Students in Cameroon: A Cross Sectional Study. J Metabolic Synd 7: 236. doi: $10.4172 / 2167-0943.1000236$

Page 3 of 6

and central obesity $(\mathrm{OR}=0.195 \% \mathrm{CI}: 0.2-0.3, \mathrm{P}=0.0000)$, compared to women.

\begin{tabular}{|c|c|c|c|c|c|c|c|c|c|}
\hline & & \multicolumn{2}{|c|}{ Overweight } & \multicolumn{2}{|c|}{ Obesity } & \multicolumn{2}{|c|}{ Central obesity } & \multicolumn{2}{|c|}{ Metabolic } \\
\hline \multicolumn{2}{|c|}{ Study population (203) } & 23.15 & & 3.94 & & 16.75 & & 11.33 & \\
\hline \multirow[t]{2}{*}{ Sex } & Male (116) & 17.24 & \multirow[t]{2}{*}{$P<0.05$} & 0 & \multirow[t]{2}{*}{$P<0.001$} & 4.31 & \multirow[t]{2}{*}{$P<0.001$} & 5.17 & \multirow[t]{2}{*}{$P<0.01$} \\
\hline & Female (87) & 31.03 & & 9.2 & & 33.33 & & 19.54 & \\
\hline \multirow[t]{3}{*}{ Ages } & $15-18(54)$ & 12.96 & \multirow[t]{3}{*}{$P=0.12$} & 3.7 & \multirow[t]{3}{*}{$P=0.8$} & 9.26 & \multirow[t]{3}{*}{$P=0.13$} & 5.56 & \multirow[t]{3}{*}{$P<0.05$} \\
\hline & $19-22(108)$ & 24.21 & & 4.21 & & 20 & & 10.19 & \\
\hline & $23-25(33)$ & 30.3 & & 6.06 & & 24.24 & & 21.95 & \\
\hline
\end{tabular}

Table 1: Prevalence of overweight, obesity and metabolic syndrome among study population: Sex and age effects.

There was a significantly higher prevalence of metabolic syndrome in subgroups with high frequency (3 to 4 days per week) of consumption of some foods, compared to subgroups with lower frequency of consumption (1 to 2 days per week) (Table 2). There were significant association of metabolic syndrome with a high frequency of consumption of the following foods (Table 3): "Koki" $(\mathrm{OR}=9.9,95 \% \mathrm{CI}$ : 7.09-14.04, $\mathrm{P}=0.0000)$, "Achu soup"( $\mathrm{OR}=7.3$, 95\% CI: 4.4-12.3, $\mathrm{P}=0.0000)$, corn couscous $(\mathrm{OR}=5.64,95 \% \mathrm{CI}$ : 4.34-7.33, $\mathrm{P}=0.0000)$, grilled pork $(\mathrm{OR}=3.3, \quad 95 \% \quad \mathrm{CI}: \quad 2.7-4.2, \quad \mathrm{P}=0.0000)$ "Ndolè"
$(\mathrm{OR}=2.4,95 \% \mathrm{CI}: 1.9-3.05, \mathrm{P}=0.0000)$, avocado and "safous"( $\mathrm{OR}=1.5$, 95\% CI: $1.4-1.7, \quad \mathrm{P}=0.0000)$, salads $(\mathrm{OR}=1.3, \quad 95 \% \quad \mathrm{CI}:$ $1.1-1.4, \mathrm{P}=0.0000)$. The prevalence of metabolic syndrome was also higher in the subgroup of heavy alcohol consumers (3-4 days/week; $\mathrm{OR}=2.9,95 \%$ CI: 1.9-4.3, $\mathrm{P}=0.0000$ ); (large amount ( 3 beers) $\mathrm{OR}=1.2$, 95\% CI: $1.2-1.3, \quad \mathrm{P}=0.0000)$. At the contrary, the prevalence of metabolic syndrome was lower in subgroups with high frequency of green vegetables consumption $(\mathrm{OR}=0.4,95 \% \mathrm{CI}$ : $0.2-0.3, \mathrm{P}=0.0000$ ).

\begin{tabular}{|c|c|c|c|c|c|}
\hline Dietary/lifestyle habits & $\begin{array}{l}\text { Prevalence metabolic } \\
\text { syndrome }\end{array}$ & of P-values & Dietary/lifestyle habits & $\begin{array}{l}\text { Prevalence metabolic } \\
\text { syndrome }\end{array}$ & of P-values \\
\hline Koki (51) & & 0.023 & Green vegetables (97) & & 0.016 \\
\hline 1-2 days/week & $2.20 \%$ & & 1-2 days/week & $75 \%$ & \\
\hline \multirow[t]{2}{*}{ 3-4 days/week } & $40 \%$ & & 3-4 days/week & $16.70 \%$ & \\
\hline & & & More than 4 days/week & $8.30 \%$ & \\
\hline Achu soup (31) & & 0.01 & Salads & & 0.031 \\
\hline 1-2 days/week & $3.40 \%$ & & 1-2 days/week & $13.60 \%$ & \\
\hline 3-4 days/week & $50 \%$ & & 3-4 days/week & $66.70 \%$ & \\
\hline Corn couscous (82) & & 0.012 & Grilled pork meat & & 0.04 \\
\hline 1-2 days/week & $5.30 \%$ & & Yes (147) & $9.30 \%$ & \\
\hline 3-4 days/week & $42.90 \%$ & & No (56) & $22.60 \%$ & \\
\hline Ndolè (47) & & 0.039 & Alcohol (77) & & 0.021 \\
\hline 1-2 days/week & $11.60 \%$ & & 1-2 days/week & $10.70 \%$ & \\
\hline \multirow[t]{5}{*}{ 3-4 days/week } & $50 \%$ & & 3-4 days/week & $100 \%$ & \\
\hline & & & Number of beers & & 0.039 \\
\hline & & & 1 beer & $6.30 \%$ & \\
\hline & & & 2 beers & $18.20 \%$ & \\
\hline & & & 3 beers & $50 \%$ & \\
\hline Avocado and "safous" (60) & & 0.003 & Physical activity & & 0.1 \\
\hline
\end{tabular}


Citation: Dabou S, Telefo PB, Leonard Sama F (2018) Evaluation of Dietary Habits and Lifestyle on the Prevalence of Metabolic Syndrome and Obesity in Undergraduate University Students in Cameroon: A Cross Sectional Study. J Metabolic Synd 7: 236. doi: $10.4172 / 2167-0943.1000236$

Page 4 of 6

\begin{tabular}{|l|l|l|l|l|l|}
\hline $1-2$ days/week & $11.10 \%$ & & Yes & $9.30 \%$ \\
\hline $3-4$ days/week & $57.10 \%$ & & No & $17 \%$ & \\
\hline & & & Physical activity & 5.1 \\
\hline & & & $3-2$ days/week & $57.10 \%$ & $37.70 \%$ \\
\hline & & & More than 4 days/week & $7.10 \%$ & \\
\hline Ice creams (17) & & 0.01 & & & \\
\hline $1-2$ days/week & & & & & \\
\hline $3-4$ days/week & $0.00 \%$ & & & & \\
\hline
\end{tabular}

Table 2: Variations of metabolic syndrome prevalence with dietary/lifestyle habits.

\begin{tabular}{|c|c|c|c|}
\hline & Obesity & Central obesity & Metabolic syndrome \\
\hline Dietary/Lifestyle habits & \multicolumn{3}{|l|}{ Odds ratios ( $95 \%$ confidence interval) } \\
\hline Gender (Male/Female) & $0.09(0.06-0.1) ; P=0.0000$ & $0.1(0.08-0.1) ; P=0.0000$ & $0.2(0.2-0.3) ; P=0.0000$ \\
\hline Koki (51) (Regular/low) & I & 1 & $9.9(7.09-14.04) ; P=0.0000$ \\
\hline Achu soup* (31) (Regular/low) & */ & */ & 7.3 (4.4-12.3); P=0.0000 \\
\hline Corn couscous (82) (Regular/low) & l & l & 5.64 (4.34-7.33); $P=0.0000$ \\
\hline Ndolè (47) (Regular/low) & 1 & 1 & $2.4(1.9-3.05) ; P=0.0000$ \\
\hline Avocado and Safous (60) (Regular/low) & l & l & $1.5(1.4-1.7) ; P=0.0000$ \\
\hline Ice creams (17) (Regular/low) & 1 & l & I \\
\hline Green vegetables (97) (Regular/low) & 1 & 1 & $0.4(0.3-0.46) ; P=0.0000$ \\
\hline Salads* (Regular/low) & */ & l & $1.3(1.1-1.4) ; P=0.0000$ \\
\hline Grilled pork meat (yes/no) & l & l & $3.3(2.7-4.2) ; P=0.0000$ \\
\hline $\begin{array}{l}\text { Alcohol }^{*} \text { (77) (heavy/light) Amount of beer } \\
\text { consumed (large/few) }\end{array}$ & */ & l & $\begin{array}{l}2.9(1.9-4.3) ; \quad P=0.00001 .2 \\
(1.2-1.3) ; P=0.0000\end{array}$ \\
\hline Green vegetables* $(97)$ (Regular/low) & *I & l & $0.2(0.2-0.3) ; P=0.0000$ \\
\hline Salads (Regular/low) & I & l & 9.9 (7.09-14.04); P=0.0000 \\
\hline Grilled pork meat (yes/no) & l & I & 7.3 (4.4-12.3); $P=0.0000$ \\
\hline Number of meal/day (More than 4: yes/no) & $5.1(3.07-8.4) ; P=0.0000$ & l & I \\
\hline $\begin{array}{l}\text { Watching TV time (More than } 6 \mathrm{~h} / \text { day } / 2-3 \mathrm{~h} / \\
\text { day) }\end{array}$ & 4.9 (2.8-7.09); $P=0.0000$ & 1 & l \\
\hline Nibbling (yes/no) & l & $3.7(3.0-4.5) ; P=0.0000$ & I \\
\hline
\end{tabular}

Table 3: Risk of metabolic syndrome and obesity in relation to gender and lifestyle habits.

Concerning obesity, we found it associated with the number of meal per day, watching TV time and nibbling. The prevalence of obesity was higher in subgroups of participants eating more than four meals per day $(\mathrm{OR}=5.1,95 \% \mathrm{CI}: 3.07-8.4, \mathrm{P}=0.0000)$. It was also higher in subgroups of participants spending more than 6 hours per day on TV watching, compared to those spending only 2 to 3 hours $(\mathrm{OR}=4.9,95 \%$
CI: 2.8-7.09, $\mathrm{P}=0.0000$ ). Similarly, the prevalence of central obesity is higher in participants who nibble compare to those who do not $(\mathrm{OR}=3.7,95 \%$ CI: 3.0-4.5, $\mathrm{P}=0.0000)$. 
Citation: Dabou S, Telefo PB, Leonard Sama F (2018) Evaluation of Dietary Habits and Lifestyle on the Prevalence of Metabolic Syndrome and Obesity in Undergraduate University Students in Cameroon: A Cross Sectional Study. J Metabolic Synd 7: 236. doi: $10.4172 / 2167-0943.1000236$

Page 5 of 6

\section{Discussion}

This study was conducted to determine the prevalence of obesity and metabolic syndrome on a sample of Cameroonian youth and their relationship with dietary habits and lifestyle. The prevalence of overweight and obesity in our study are similar to those obtained by Ewane et al on Cameroonian students attending the University of Douala (3.9\% for obesity and $19.4 \%$ for overweight) [9]. The one of metabolic syndrome is lower than the one reported in the general population of Cameroon: $19.8 \%$ in 2008 [16] and 17.4\% in 2014 [7]. Given the fact that metabolic syndrome is shown to increase with age $[16,17]$, the observed differences are explained by the elevated mean age of individuals in these studies populations compare to ours. As suggested by many other authors [17,18], women in our study appeared to be more exposed to obesity and metabolic syndrome than men. This can be the consequence of their more sedentary lifestyle, added to the modifications of their nutritional habits, coupled with hormonal influences that promote fat storage [19]. Our study indicated that there was an association between metabolic syndrome and inappropriate consumption ( 3 to 4 days per week) of "Koki"( $\mathrm{OR}=9.9$, 95\% CI: 7.09-14.04, $\mathrm{P}=0.0000)$, "Achu soup"( $\mathrm{OR}=7.3$, 95\% CI: 4.4-12.3, $\mathrm{P}=0.0000)$, corn couscous $(\mathrm{OR}=5.64,95 \% \mathrm{CI}: 4.34-7.33, \mathrm{P}=0.0000)$ "Ndole" (OR=2.4,95\% CI: 1.9-3.05, $\mathrm{P}=0.0000)$, avocado and "safous" $(\mathrm{OR}=1.5,95 \%$ CI: 1.4-1.7, $\mathrm{P}=0.0000)$, salads $(\mathrm{OR}=1.3,95 \% \mathrm{CI}$ : $1.1-1.4, \mathrm{P}=0.0000)$. A high frequency of consumption of those meals therefore appears to be a risk factor for developing metabolic syndrome. This may be due to their excess energy supply, compared to the body needs. Indeed, "Achu soup" and "koki" are traditional dishes from west Cameroon made up with large amount of palm oil. This vegetable oil contains high percentage of saturated fatty acids, which are responsible of its increased cardiometabolic risk [20]. "Ndolè", contain large amounts of groundnuts (Arachis hypogea L.) which is an oleaginous plant [21], containing high amount of lipids that can also contributes to an increased cardiometabolic risk by inducing excess fat storage on adipose tissues. This can also explain the association observed with avocado (fruits of Persea americana) and safous (fruits of Dacryodes edulis) that are also rich in lipids and can impair energy balance and have harmful effects on health, despite their unsaturated fatty acid content $[21,22]$. Besides, foods rich in carbohydrates like Corn couscous and ice creams [21], can also contributes to the induction of metabolic syndrome, by providing substrate to de novo lipogenesis at the end of their digestion process [23]. Our study thus provides preliminary data, for the definition of optimal diet recommendations, with frequency cut off points for healthy consumption of homemade and even processed foods.

The association of pork intake with metabolic syndrome $(\mathrm{OR}=3.3$, 95\% CI: 2.7-4.2, $\mathrm{P}=0.0000$ ) has been previously reported, even though precise mechanism is not yet described [24]. The preventive effects of green vegetables on cardiometabolic risk (by ameliorating bowel movement and increasing satiety) [21] has been observed in our study, as well as the nocive effects of high alcohol intake, especially when associated with a high fat intake [25-27]. Excess energy intake (high number of meal per day: $\mathrm{OR}=5.1,95 \% \mathrm{CI}$ : 3.07-8.4, $\mathrm{P}=0.0000$; nibbling: $\mathrm{OR}=3.7,95 \% \mathrm{CI}$ : $3.0-4.5, \mathrm{P}=0.0000)$, and activities promoting sedentarity like watching television (more than 6 hours/day: $\mathrm{OR}=4.9$, 95\% CI: 2.8-7.09, $\mathrm{P}=0.0000$ ) are shown in this study to be more and more integrated in our population lifestyle, especially on freshmen. Prevention campaign targeting youth may therefore be multiplied with special concern on those lifestyle aspects.

\section{Conclusion}

Metabolic syndrome and obesity are associated in young Cameroonians to some dietary and lifestyle habits. High frequency of consumption of some homemade foods, fruits (avocado and "safou"), salads and high alcohol intake can be considered as risk factors for metabolic syndrome; whereas regular consumption of green vegetables may prevent it. High number of meal per day and high frequency of TV watching increased the risk of obesity. This study provides evidence that may justify public health interventions on youth for the efficient prevention of cardiovascular diseases and type 2 diabetes. Further studies may be conducted to determine macro and micronutrients composition of homemade foods as well as their energy supply, for the definition of optimal diet recommendations in our Cameroonian context.

\section{Declarations}

\section{Ethics approval and consent to participate}

The Helsinki declaration on biomedical ethic was respected. The "Cameroon Bioethics Initiative Ethics Review and Consultancy Committee" (CAMBIN-ERCC) approved the study design with a clearance at the number: CBI/369/ERCC/CAMBIN/1079. All the participants provided a signed informed consent form.

\section{Availability of data and materials}

The datasets used and/or analyzed during the current study are available from the corresponding author on reasonable request.

\section{Competing interests}

The authors declare that they have no competing interests.

\section{Authors' contributions}

DS and TPB designed the study. SD and SLF performed laboratory analysis. DS and TPB performed statistical analysis. DS wrote manuscript. TPB and SLF reviewed manuscript draft. All authors read and approved the final version of the manuscript.

\section{Acknowledgements}

We kindly acknowledge the Medical center of the University of Dschang for providing technical assistance for data collection.

\section{References}

1. Alberti KG, Eckel RH, Grundy SM, Zimmet PZ, Cleeman JI et al. (2009) Harmonizing the metabolic syndromea joint interim statement of the international diabetes federation taskforce on epidemiology and prevention; national heart, lung, and blood institute; American heart association; world heart federation; international atherosclerosis society; and international association for the study of obesity. Circ 120: 1640-1645.

2. Roberts CK, Hevener AL, Barnard RJ (2013) Metabolic Syndrome and Insulin Resistance: Underlying Causes and Modification by Exercise Training. Compr Physiol 3: 1-58.

3. Shiriki K (2004) Cultural Differences as Influences on Approaches to Obesity Treatment. Handbook of Obesity second edition. edited by Bray AG, Bouchard C. Marcel Dekker, New York, USA. 
Citation: Dabou S, Telefo PB, Leonard Sama F (2018) Evaluation of Dietary Habits and Lifestyle on the Prevalence of Metabolic Syndrome and Obesity in Undergraduate University Students in Cameroon: A Cross Sectional Study. J Metabolic Synd 7: 236. doi: $10.4172 / 2167-0943.1000236$

Page 6 of 6

4. Conrad PE, Church ST (2015) Evaluation of a Voluntary Worksite Weight Loss Program on Metabolic Syndrome. Metab Syndr Relat Disord 13: 406-414.

5. Zeba AN, Delisle H, Renier G, Savadogo B, Baya B, et al. (2012) The double burden of malnutrition and cardiometabolic risk widens the gender and socio-economic health gap: a study among adults in Burkina Faso (West Africa). Public Health Nutr 30: 1-10.

6. Correia J, Pataky Z, Golay A (2014) Comprendre l'obésité en Afrique: poids du développement et des représentations. Rev Med Suisse 10 : 712-716.

7. Ntentie FR, Ngondi JL, Azantsa G (2014) Urbanization and Metabolic Syndrome in Cameroon: Alertness on Less Urbanised Areas. Endocrinol Metab Synd 3: 137-145.

8. OMS: Organisation Mondiale de la Santé (2003) Obésité: prévention et prise en charge de lépidémie mondiale, Rapport technique. Genève : Suisse 894 : 15-65.

9. Ewane EM, Mandengue SH, Priso BE, Tamba SM, Dzudie A, et al. (2012) Dépistage des maladies cardiovasculaires chez des étudiants de l'Université de Douala et influence des activités physiques et sportives. Pan African Medical Journal 11: 77-83.

10. Briggs MS, Spees C, Bout-Tabaku S, Taylor AC, Eneli I, et al. (2015) Cardiovascular Risk and Metabolic Syndrome in Obese Youth Enrolled in a Multidisciplinary Medical Weight Management Program: Implications of musculoskeletal Pain, cardiorespiratory fitness, and health-related quality of life. Metab Syndr Relat Disord 13: 102-109.

11. Miller MJ, Kaylor MB, Johannsson M, Bay C, Churilla RJ (2014) Prevalence of Metabolic Syndrome and Individual Criterion in US Adolescents: 2001-2010 National Health and Nutrition Examination Survey. Metab Syndr Relat Disord 12: 527-532.

12. Peltzer K, Pengpid S, Samuels AT, Özcan KN, Mantilla C, et al. Prevalence of Overweight/Obesity and Its Associated Factors among University Students from 22 Countries. Int J Environ Res Publ Health 11: 7425-7441.

13. Kaneda T, Naik R, Baldwin W (2015) Non-communicable Diseases Risk Factors Among Young People in Africa.

14. Fossati P (1982) Principe L.Triglycérides PAP, freeze dried. Clinical Chemistry 28: 2077.

15. Trinder P. (1969) Determination of glucose in blood using glucose oxidase with alternative oxygen acceptor. Annual Clinical of Biochemistry 6: 24-27.
16. Enyegue MD, Ngondi JL, Fomekong (2008) Prediction and Prevalence of Metabolic Syndrome in Overweight and Obese Subjects in Cameroon. Int j pharm biomed res 20: 470-475.

17. Fouda Bita AA, Lemogoum D, Owona Manga J (2012) Epidémiologie de l’obésité en milieu du travail à Douala Cameroun. Rev Med Brux 33: 131-137.

18. Choukem SP, Kengne AP, Nguefack ML, Mboue-Djieka Y, Nebongo D, et al. (2015) P252 Tendancessur 5 ans de lobésité et de la pressionartérielle chez des jeunesadultes en milieu urbaincamerounais. Diabetes \& metabolism 41: 97.

19. Lombard C, Teede H (2009) Prévenir l'obésité chez les femmes de tous âges - une priorité de santé publique. Diab Voice 54: 12-16.

20. Rosqvist F, Iggman D, Kullberg J, Cedernaes J, Johansson HE, et al. (2014) Overfeeding Polyunsaturated and Saturated Fat Causes Distinct Effects on Liver and Visceral Fat Accumulation in Humans. Diabetes 63: 2356-2368.

21. Pamplona-Roger G (2004) La santé par les aliments, Madrid : Safeliz.

22. Silout T, Rocquelin G, Gallon G (2000) Contribution à la caractérisation des safous

23. (Dacryodes edulis) d'Afrique centrale. Rivista Italianadellesostanzegrasse 77: 85-89.

24. Nelson LD, Cox MM (2004) Lehninger, Principles of Biochemistry. 4thedition, W. H. Freeman and company, New York.

25. Stettler N, Murphy MM, Barraj LM, Smith KM, Ahima RS (2013) Systematic review of clinical studies related to pork intake and metabolic syndrome or its components. Diabetes Metab Syndr Obes 6: 347-357.

26. Lukasiewicz E, Mennen L, Bertrais S, Arnault N, Preciosi P, et al. (2004) Alcohol intake in relation to body mass index and waist-to-hip ratio: the importance of type of alcoholic beverage. Public Health Nutr 8: 315-320.

27. Bruner EJ, Wunsch H, Marmot MG (2001) What is an optimal diet? Relationship

of macronutrient intake to obesity, glucose tolerance, lipoprotein cholesterol levels and the metabolic syndrome in the Whitehall II study. Int J Obes 25: 45-53.

28. Berr C, Chapelon-Clavel F, Daval JL, Fumeron F, Gire C, et al. (2001) Alcool, effets sur la santé, Paris, Inserm. 